\section{Peddling prosperity}

Philip Gummett

Science, Technology and the British Industrial 'Decline', 1870-1970. By David Edgerton. Cambridge University Press: 1996. Pp. 88. £17.95, \$29.95 (hbk); £6.25, $\$ 9.95$ (pbk).

AT the end of a lecture on the decline of Britain as a world power, a colleague was recently accused by a student of being unpatriotic. The lecturer reminded the student that his starting point had been the reign of King Henry VIII. Decline is a relative matter, as David Edgerton, working over a shorter period, labours to establish. That those who were initially strongest find their dominance increasingly challenged by newcomers does not necessarily mean that they are doing all that badly.

In 69 pages of text, Edgerton attempts a lively demolition of what he takes to be a range of orthodox positions on the "problem" of British industrial "decline", and the extent to which that decline is due to failures to invest in, or properly apply, science and technology. His targets include, among many others, C. P. Snow, Corelli Barnett, Martin Wiener and assorted "technocratic" (in Edgerton's usage of the term) writers on science policy, including Christopher Freeman.

Edgerton argues that many of the participants in this debate have confused relative decline with "failure". This, he suggests, has led them to overlook the fact that, until the $1960 \mathrm{~s}$, Britain was the second-largest industrial economy in the world, with investment in science and technology to match, and a record in technological innovation at least as good as that of Germany. Suggestions of an antiscience culture in British boardrooms and government are met with statistics about the percentage of company directors with technical backgrounds, or the degree of both industrial and state funding of research and development (R\&D).

Useful original data are presented to show that British industrial spending on R\&D from the 1930 s to the 1970 s was much higher than is often assumed, and that most large manufacturing companies were doing R\&D by the 1930 s, even if the same was not true of smaller companies. He also emphasizes the volume of government spending on R\&D, particularly on military $R \& D$, between the world wars. This was dramatically so in the case of aviation: the Royal Air Force in the 1930s had hundreds of aircraft, compared with Imperial Airways having mere tens; the Air Ministry was easily the largest government spender on R\&D. Similarly, in the $1940 \mathrm{~s}$ and $1950 \mathrm{~s}$, its successor, the Min- istry of Supply, spent more than private industry on R\&D. the more simplistic claims that have been made about the centrality of science to wealth creation. But in addressing so large a subject in so short a book, Edgerton is forced to compress brutally his own arguments (even the bibliography is shorn of publishers' names). As a result, they often come across with less subtlety or precision than might be thought desirable. For example, he makes the apparently revisionist claim that "[d]espite the protests of scientists, and the laments of historians of 'science policy', the British state usually spent more on warlike $R \& D$ than on civil $\mathrm{R} \& \mathrm{D}$, and never concentrated its funding of R\&D in one department of state [he is referring to the Department of Scientific and Industrial Research]". This not only contains an unfortunate ambiguity about the subject of the protests and laments
This is a valuable corrective to some of
"THEIR apparatus was of a very homely character, and appears to have been devised under the necessity which ingenious men in want of capital are apt to experience." In The Infernal Diver, John Bevan reinstates Charles and John Deane as the inventors of the diving helmet, seen here in a sketch made around 1830 by Simon Goodrich, chief mechanist of the Royal Navy. In detailing the way in which the helmet was first applied to salvage, treasure and military uses, the author provides insight into the process of technological nineteenth century - an age when the amateur inventor, working with limited resources, was an important figure in industry. Submex, 21 Roland Way, London SW7 3RF, UK. £60. hunting, civil engineering development in the early but, more importantly, also seems to overlook material in at least one of the two sources he cites that shows that these historical mistakes were not in fact universally made.

He later challenges the claim by some analysts that the mistakes made over large-scale investments in the 1960s and 1970s in civil high-technology projects lay in their choice of sector (principally aerospace and nuclear power) rather than in the volume of investment itself. He does so by asserting that the trouble was that "government, scientists and engineers all genuinely believed that civil aerospace and nuclear power were the technologies of the future". Really? Not a single doubter among all those people?

This is a pity, because the target audience, "students approaching a subject for the first time, and... their teachers", deserve a more nuanced analysis than the book often manages and which, had more space been available, the author could have provided. So although the book will undoubtedly be of value to them, it needs to be treated with as much care as its author would attach to those he criticizes.

Philip Gummett is in the Department of Government, University of Manchester, Manchester M13 9PL, UK.

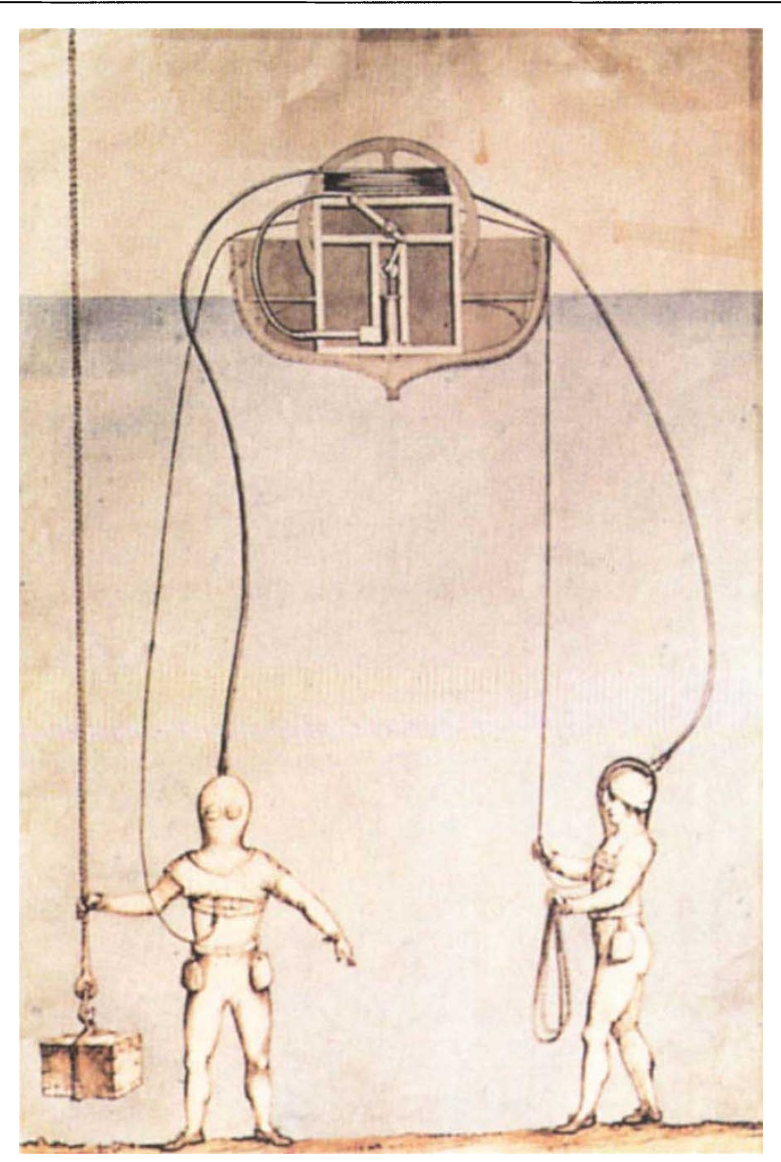

